\title{
Corrigendum: Effects of Gender of Reciprocal Chromosomal Translocation on Blastocyst Formation and Pregnancy Outcome in Preimplantation Genetic Testing
}

\section{OPEN ACCESS}

Approved by:

Frontiers Editorial Office

Frontiers Media SA, Switzerland

*Correspondence:

Yi-le Zhang

Iuna020996@126.com

${ }^{\dagger}$ These authors have contributed equally to this work

Specialty section: This article was submitted to

Reproduction, a section of the journal

Frontiers in Endocrinology

Received: 25 October 2021 Accepted: 25 October 2021 Published: 10 November 2021

Citation:

Song $H$, Shi $H$, Yang E-t, Bu Z-q, Jin Z-q, Huo M-Z and Zhang Y-I (2021)

Corrigendum: Effects of Gender of

Reciprocal Chromosomal Translocation on Blastocyst Formation and Pregnancy Outcome in Preimplantation Genetic Testing.

Front. Endocrinol. 12:788988. doi: 10.3389/fendo.2021.788988
Hui Song ${ }^{1,2+}$, Hao Shi ${ }^{1,2+}$, En-tong Yang ${ }^{1,2+}$, Zhi-qin Bu ${ }^{1,2}$, Zi-qi Jin ${ }^{1,2}$, Ming-zhu Huo ${ }^{1,2}$ and Yi-le Zhang ${ }^{1,2 *}$

${ }^{1}$ Reproductive Medicine Center, First Affiliated Hospital of Zhengzhou University, Zhengzhou, China, ${ }^{2}$ Henan Key Laboratory of Reproduction and Genetics, First Affiliated Hospital of Zhengzhou University, Zhengzhou, China

Keywords: biopsy, clinical pregnancy rate, maternal age, paternal age, preimplantation genetic testing, reciproca translocation, blastocyst formation rate, aeuploidy rate

\section{A Corrigendum on}

Effects of Gender of Reciprocal Chromosomal Translocation on Blastocyst Formation and Pregnancy Outcome in Preimplantation Genetic Testing

By Song H, Shi H, Yang E-t, Bu Z-q, Jin Z-q, Huo M-z and Zhang Y-l (2021). Front. Endocrinol. 12:704299. doi: 10.3389/fendo.2021.704299

There is an error in the Funding statement. The correct number for the National Natural Science Foundation of China grant is 31970799 .

The authors apologize for this error and state that this does not change the scientific conclusions of the article in any way. The original article has been updated.

Publisher's Note: All claims expressed in this article are solely those of the authors and do not necessarily represent those of their affiliated organizations, or those of the publisher, the editors and the reviewers. Any product that may be evaluated in this article, or claim that may be made by its manufacturer, is not guaranteed or endorsed by the publisher.

Copyright $\odot 2021$ Song, Shi, Yang, Bu, Jin, Huo and Zhang. This is an open-access article distributed under the terms of the Creative Commons Attribution License (CC BY). The use, distribution or reproduction in other forums is permitted, provided the original author(s) and the copyright owner(s) are credited and that the original publication in this journal is cited, in accordance with accepted academic practice. No use, distribution or reproduction is permitted which does not comply with these terms. 